\title{
Students with Spinal Cord Injury on US Campuses: Areas of Improvement
}

\author{
Justine Noel \\ Department of Educational Leadership \\ Saint Joseph's University, USA
}

\begin{abstract}
Spinal Cord Injuries (SCI) are not just traumatic experiences but also drastically change the life of the suffering individuals. Returning to school constitutes as one of the challenges that involve a greater degree of adaptation including but not limited to physical, emotional, social and learning revamping. This paper studies the existing literature on difficulties faced by people suffering from an SCI after returning to school. The dissatisfaction of the disabled students is studied at various universities, which are in compliance with the ADA regulations, and measures are recognized to make the overall learning experience and school environment better. Furthermore, the roles and duties of the disability offices are studied, and the importance of their actions and involvement is recognized. Four areas of improvement are presented to improve the quality of education and schooling experience for students with an SCI. This paper further establishes the need to create awareness of an SCI amongst the faculty in order to provide a better-adapted learning environment.
\end{abstract}

\section{Introduction}

A Spinal Cord Injury can change the approach towards someone's life, physically as well as emotionally, and it requires a substantial amount of adaptation. In February 2015, the National Spinal Cord Injury Statistical Center (NSCISC) at the University of Alabama published a report stating: "The annual incidence of SCI ... is approximately 40 cases per million population in the U.S" [1]. Among this population, $16.1 \%$ are reported being students 1 year after injury. With the several changes that an SCI causes to individuals, returning to school after their injury can be a challenge. How much adaptation will be needed to access the campus with a wheelchair? Is the university ready to welcome students with an SCI?

Institutions are by law compelled to apply the Section 504 anytime one of their students declare their disabilities. However, the quality of the accommodations proposed by the institutions does not always reflect in a students' achievement. A better understanding of Section 504 of the Rehabilitation Act of 1973 defines a person with a disability as:

\footnotetext{
"Any person who has a physical or mental impairment that substantially limits one or more of that person's major life activities, or a person who has a record of such impairment, or a person who is regarded as having such impairment." (Section 504 Regulations, 29 U.S.C. \$ 794) [2].
}

Indeed, Section 504 includes postsecondary educational services, admissions, academic and athletics programs, extracurricular activities, tests, housing, and counseling. The most important provision of Section 504 and the American Disability Act is equal opportunity. That is why schools are required to accommodate the academic requirements, other rules, and policies to avoid discrimination against students with disabilities.

After thinking about and discussing some of the barriers that arise, this study will try to propose answers to the following question: How can universities improve to meet the needs of students with a Spinal Cord Injury after they return to school?

There are three main purposes of the study. The first goal is to identify and understand the needs of students with a Spinal Cord Injury after they return to school. Second, it is important during the study to recognize what is available within the universities for these students. Regarding the previous observations, the third goal of the study is to provide solutions for universities that will offer fair education to everyone without discrimination, especially for students with a Spinal Cord Injury.

Regarding the research question, and based on the readings from Leedy, the research design that seems appropriate is the qualitative case study. Leedy defines the case study as:

A case study may be especially suitable for learning more about a little known or poorly understood situation. It can also be appropriate for investigating how an individual or program changes over time, perhaps as the result of certain conditions or interventions" [3] 
The process of a case study starts with an intensive collection of data on the participants. This study is composed of two groups of participants regarding the topics. One group is made of students with an SCI and the second group is the remainder of the population that constitutes universities. The area of investigation is Philadelphia, Pennsylvania. Nevertheless, if during the first weeks of data collection, it appears that the sample is too small, the study will be increased to the state level. After the collection of the data and the analysis of the results, it would be possible to propose solutions that will be shaped from the studies of real life experiences. The answers, feelings, and comments of students with a disability compose valuable resources in order to draw accurate solutions.

The uniqueness of the study appeared during the review of the literature. The existing literature review emphasized studies that have been conducted on a cross-topic approach involving students with any kind of disabilities and their return to school after the injury. It is noteworthy that disabilities are different from one another. It is crucial to understand each need related to the disability to propose adequate support.

\section{Literature Review}

It is important to understand that solutions to the problem of the study will be determined with the help of two elements. The first element is to understand the needs of students with an SCI who are returning to school after their injury. The second element is the settings of the universities. To be more precise, the settings of the university are the areas that it is composed of such as buildings, faculty, and staff, facilities, teaching methods etc. Several articles are particularly relevant for the research's topic.

After reviewing these articles, four recurrent categories are highlighted: American Disability Act (ADA) compliance, Disability Services (DS), Classroom environment (that includes teaching methods, instructional materials, and curriculum) and Universal Design (UD). These categories have been cited in all of the articles and are presented as general agreements. The authors generally criticized the compliance of the ADA within universities, which is not qualitatively respected. Mallory Angeli [3] found in her study that most of the campuses in California are not able to meet the minimum requirement of the $\mathrm{ADA}$ compliance. A lack of funding is the reason it is difficult to implement these requirements. The same results have been found by Simonson, Glick, and Nobe [4] in their article "Accessibility at a public university: student's perceptions." The authors studied the feasibility of some of the implementation required by the ADA. Cory [5] brings up another point of view of the ADA compliance. She scrutinizes the ADA rules and guidelines and identifies them as well-written but not enough, resulting in students with disabilities being not as well recognized and accepted on campuses as compared to gay, lesbian, bisexual and transgender students. West et al., [6] found that Section 504 makes a difference between the accessibility of programs and environment. Section 504 emphasizes on programs and not environments. Moreover, students with disabilities have different needs, as their disabilities can be physical, visual, hearing and/or cognitive. These limitations could be a barrier for students with different kind of disabilities. This statement shows the limitations of the Section 504 to provide a completely accessible institution for students with disabilities. According to the National Center for Education Statistics (2015), 86.4\% of the students declared that they have encountered barriers in their postsecondary education as a result of being a student with a disability. Studies have been made in the past to determine the satisfaction of accessibility on campus for students with disabilities. In 1993, West et al., [6] conducted a study on students with different disabilities such as mobility, hearing and visual impairment, and learning disabilities. The results of the survey reported that students with disabilities were unaware about the special services available on campus. Also, these same students were encountering multiple troubles such as difficulties to access buildings, inaccessibility of the ramps due to being in bad conditions, requiring extra travel to access buildings, or classroom's size not being appropriate.

Most of the authors introduce and propose the Universal Design (UD) concept defined by Ron Mace [7] as a way of "designing all products and the built environment to be aesthetic and usable to the greatest extent possible by everyone, regardless of their age, ability, or status in life." Interesting points that Salmen [8] discusses regarding his study are the levels of guidance that are required when building including laws, regulations, and standards. Salmen claims that Universal Design is different from accessibility. On one hand, UD does not have a range of standards. This means that there are no laws that require universities to provide areas with UD. On the other hand, accessibility is about complying with law requirements. Bryan and Myers [9] discuss the topic of architectural problems. In order to make campuses physically accessible for all students, the question of how the campus environment is designed is also important. Cory [5] supports the idea of a UD method to further strengthen the integration of all students. The UD concept could be an optimum solution to create an inclusive environment and promote equality.

In order for a student to perform well academically, it is necessary to provide an adequate environment as well as a quality of education. Classroom environment, both teaching methods, and 
instructional materials need to be adapted to their greatest possibility. Angeli [3] found that campus communities are very often not aware and not prepared to cope with students with disabilities. A lack of knowledge comes from the faculty, staff and other students on campuses. For the teachers' example, the author's research draws attention to their lack of training and preparation. Cole, Christ, \& Light [10] also explained in their article that institutions are not obliged to change an entire existing curriculum to accommodate students with disabilities. From another point of view, Simonson et al. [4] make an interesting correlation between the perceptions of accessibility from students with disabilities and the impact(s) that may arise on their quality of education. Following the responses of students with disabilities, the perception of an accessible campus would increase the quality of their education. The main issue that these students were facing was the incompetence of the teachers. Results from West $\&$ al's survey shows that the perception of the students with a disability regarding the accommodations from the teachers is rather negative: most of the teachers did not have any training to provide adapted teaching methods for students with disabilities [6].

The protection of students with disabilities, under the Section 504, leads to the accommodation of their education. It is important at the beginning to define their needs that their disability requires. The most qualified people on campus who can help students with disabilities are a part of the Disability Services (DS). It is present in every university. An important finding is the necessity of coordination between students with disabilities, universities faculty, and DS to reach an adequate environment for students with an SCI after they return to school following their injury. Anne Bryan and Karen Myers [9] recognize the existence of DS at each university. Nevertheless, they are questioning their operations because each university decides who is responsible for students with disabilities. This point is also emphasized in two other articles. Cory [5] notes that a coordination of work between the faculty, the students and DS is the key to finding common solutions that would benefit the students in need.

One of the main topics of the research proposal is concentrating on students with an SCI. Nevertheless, after reviewing original studies on the subject, it appears that the studies do not point out this particular injury. It focuses on students with any kind of disabilities. However, the fact that most of the research conducted by the authors is relevant for mobility impairment means that the results of the studies will still be helpful for students with an SCI.

\section{Methodology}

This study is being conducted in order to provide solutions to universities in improving the needs of students with a Spinal Cord Injury (SCI) after they return to school. After a review of the literature on the subject, it appeared in multiple areas that universities need development to propose a completely accessible place for students with an SCI in the pursuit of their education. The perceptions and the real life experiences of students with a disability will produce accurate results. Their answers and comments will be the base of the analysis. It will point out the main problems that these students may face during their way back to a university.

\subsection{Sampling}

Two groups and several sub-groups will be solicited to participate in the study. The first group will be formed with students with an SCI, enrolled in a university following the injury. The level of education, race, age, gender and socio-economic background will not be taken into consideration during the study. The universities will represent the second group. In order to facilitate the collection of the data, five sub-groups will be created.

The first sub-group is the Disability Services office. This office provides help to students with a disability during their education. The second subgroup is the faculty and staff that are connected to the students with an SCI. They will be resourceful in providing information about their experiences with the students. The IT department and library staff will be the third sub-group. Students with disabilities are assumed to be in contact with these departments for the academic materials such as special equipment, tablets, textbooks, and e-books. The fourth sub-group that will be participating is the "public safety" department. They are related to the building accesses and construction matters on-campus. Finally, the last sub-group is the campus housing staff, which helps students in finding a place to live on campus. The study of the principal groups, the universities and the students with an SCI, aims to collect data from different perspectives in order to propose precise and relevant solutions to the problem stated.

As discussed earlier, the study will be done within universities in the Philadelphia area. The Philadelphia area counts about 19 four-year colleges and universities, 10 two-year institutions and technical schools and 5 graduate institutions. All of these institutions propose programs at a higher education level. Nevertheless, if the sampling tends to be too low, the study will be extended at a state level. The number of participants expected is between 25 and 50. It is necessary to reach a sufficient number of participants in order to collect enough data. 
The students who will participate in the study will be contacted through the Disability Services office. The second group composed of the universities' staff will be reached through the heads or directors of each department.

\subsection{Data Collection}

The techniques that will be used for the data collection will be "the three E's". The Three E's are Experiencing (composed of observations and notes), Enquiring (formed with interviews and questionnaires) and Examining (which involves the making of records like audio/video recordings for example). [11] Ideally, the data collection would have to take place within an academic semester. Several weeks would be essential to build confidence between the researcher and the participants.

In research, ethics is an important question that researchers have to take into consideration. Mills [11] describes two rules of ethics as the following "participants should not be harmed in any way (...) and that researchers obtain participants' informed consent.". The participation will be volunteer-based and a first individual contact with the participants will be scheduled in order to explicitly describe the conduct of the data collection (how the interviews will be done, what kind of subjects will be addressed etc.). Underage students will have to obtain authorization from their legal representative before participating. Moreover, as interviews will be recorded, a consent form will be distributed.

All the data collected in any form will stay confidential. However, the data will not be anonymous as the researcher will be directly in contact with the participants during the interviews and/or observations.

The role of the researcher is critical during the study especially if the subject of the study is personally connected with him/her. The interpretations and analysis will be strictly transparent i.e. the researcher will have to keep an open-mind and not involve personal beliefs, emotions and point of view within the conclusions. The researcher will be the one to prepare the questions that will be used during the interviews; he/she will be in charge of taking notes and also to sort the different notes afterward. During the observations, the researcher will have the role of a passive observer. For example, if the researcher is following a student with an SCI during his/her typical school day, his/her role will be to witness how the school environment affects the student's disability.

\subsection{Data Analysis}

The data will be analyzed regarding the method proposed by Leedy [3] on page 141. For that, it will be necessary to transcript the interviews. The first step is the organization of the details of the case. The second step will be to point out principal categories, which will help to sort the data. Every other data or information that will not fit into a category will be expressed and interpreted apart. The fourth step of the data analysis is the creation of themes that should come out from the collection of the data. Finally, with the help of the main themes, it will be possible to synthesize and to draw conclusions.

It is important to note that, thanks to the two different groups from where the data are collected, a triangulation of the data will be possible. Mills [11] explains the triangulation as "collecting information in many ways rather than relying solely on one." Indeed, it will provide accurate and relevant data from different perspectives.

\section{Conclusion}

The correlation between what the universities can provide regarding an accessible campus for students with an SCI and the reality (supported by the perceptions of students with an SCI) is sometimes in opposition. Being a student is a full-time role and it involves a good organization in order to succeed academically. In higher education, students with disabilities are protected under the Section 504 of the Rehabilitation Act of 1973. Institutions have to comply with the law requirements in order to provide equal education for students with disabilities and non-disabled students. These requirements are implemented through reasonable accommodations that need to be set up between the students with disabilities and the Disability Services Offices present in every university. However, these accommodations do not always meet the need of students with disabilities. A lack of quality in the services provided can create barriers and impact student achievement.

Because a disability can affect the way of living of a student in several ways such as stress, lack of confidence, difficulties to meet school academic goals, laws are supposed to help these students to achieve as well as their non-disabled peers. Students with an SCI or any other kind of mobility impairment need to think ahead before going to their classes. Is the path secure to access my classroom? Are the automatic doors working today? All of these questions that a student with an SCI may think about are adding anxiety to their daily life, and most importantly can affect their schooling. Most of the original studies reviewed on the topic are claiming some of these problems that students with disabilities face during their education. Limitations of the accommodations can particularly affect the quality of education that a student with a disability receives. It would be interesting to think in depth about the meaning of "reasonable accommodation". Each 
student is different and his/her disability requires separate and adapted accommodations.

To go further on the research proposal without replicating what has already been done, several paths could be explored and given more information on the subject in Philadelphia and/or Pennsylvania: a concentration on students with a Spinal Cord Injury only, a student point-of-view resulting from qualitative studies and an observation of ADA compliance in the given locations.

\section{Acknowledgements}

The author of this paper would like to thank Dr. Encarna Rodriguez, Associate Professor at the Department of Educational Leadership at Saint Joseph's University (SJU) for her continued support, guidance, and the knowledge conveyed through the Educational Leaders as Researcher and Reflective Practitioner course at SJU.

\section{References}

[1] National Spinal Cord Injury Statistical Center, (2015, February). Spinal Cord Injury, facts and figures at a glance. [Data file] Retrieved from:https://www.nscisc.uab. edu/PublicDocuments/fact_figures_docs/Facts\%202015.pd $\mathrm{f}$

[2] Schraven, J., \& Jolly, J. L., (2010). Section 504 in American Public Schools: An Ongoing Response to Change. American Educational History Journal, 37(2), 419-436.

[3] Leedy, P., \& Ormrod, J., (2012). Practical research: Planning and design (10th Ed.). Upper Saddle River, NJ: Pearson Merrill Prentice Hall. (Paperback, ISBN: 978-013-269324-0)

[4] Angeli, M., \& California Postsecondary Education, C., (2009). Access and Equity for All Students: Meeting the Needs of Students with Disabilities. Report 09-15. California Postsecondary Education Commission.

[4] Simonson, S., Glick, S., \& Nobe, M. E. C., (2013). Accessibility at a public university: student's perceptions. Journal of Facilities Management, 11 (3), 198 - 209.

[5] Cory, R. C., (2011). Disability services offices for students with disabilities: A campus resource. New Directions for Higher Education (154), 27 - 36.

[6] West, M., Kregel, J., Getzel, E. E., Zhu, M., (1993). Beyond section 504: Satisfaction and empowerment of students with disabilities in higher education. Exceptional Children, 59(5), 456.

[7] Mace, R., (1997). What is universal design? The Center for Universal Design at North Carolina State University. Retrieved November 19, 2004.

[8] Salmen, J. S., (2011). Universal Design for Academic
Facilities. New Directions for Student Services, (134), 1320.

[9] Bryan, A., \& Myers, K. A., (2006). Students with Disabilities: Doing What's Right. About Campus, 11(4), 18-22.

[10] Cole, B., Christ, C., \& Light, T. R., (1995). Social Work Education and Students with Disabilities: Implications of Section. 504 AND ADA. Journal of Social Work Education, 31(2), 261-268.

[11] Mills, G. E., (2014). Action research: A guide for the teacher researcher (5th Ed.). New York: Pearson. (paperback, ISBN: 9780132887762).

[12] American Psychological Association, (2010). Concise rules of APA style (6th ed.). Washington D.C.: American Psychological Association. ISBN: 978-1-4338-0560-8 